\title{
OS DESAFIOS DA DOCÊNCIA ORIENTADA EM TEMPOS DE PANDEMIA
} THE CHALLENGES OF GUIDED TEACHING IN TIMES OF PANDEMIC

\section{Clarice Rosa Machado ${ }^{1}$, Caroline Manucelo Colpo ${ }^{2}$ e Eliane Aparecida Galvão dos Santos ${ }^{3}$}

\section{RESUMO}

Este trabalho é resultado dos estudos e da experiência vivenciada na disciplina de Docência Orientada do Mestrado Acadêmico em Ensino de Humanidades e Linguagens (MEHL/UFN). A Docência Orientada visa a contribuir com a aprendizagem do futuro docente ou a complementar a formação daqueles que já atuam na profissão, possibilitando uma articulação entre a graduação e a pós-graduação, bem como entre a teoria e prática. A atividade de docência orientada ocorreu no primeiro semestre de 2020, foi desenvolvida na disciplina de História da Moda e do Vestuário I, do Curso de Design de Moda, e na disciplina de Lógica e Argumentação I, do Curso de Filosofia, na Universidade Franciscana. Tal escolha deu-se porque as docentes orientadas têm formação inicial nos referidos cursos. Diante deste novo contexto, tem-se como objetivo discutir os desafios da Docência Orientada relativa à prática docente no ensino superior em meio a pandemia, também, apresentar os relatos das experiências de docência de duas acadêmicas do referido mestrado. A metodologia adotada para a pesquisa é bibliográfica com relatos de experiência da atividade de docência. $O$ estágio docência constitui-se como uma experiência enriquecedora e pertinente na formação profissional docente, viabilizando a construção e consolidação de conceitos e a superação de dificuldades da carreira da docência no ensino superior.

Palavras-chave: Covid-19, Ensino e aprendizagem, Modalidade remota, Pós-graduação.

\section{ABSTRACT}

This work is the result of studies and the experiences in the discipline 'Guided Teaching' from the Academic Master Course in Teaching of Humanities and Languages (MEHL/ UFN). The Guided Teaching aims to contribute to the learning of the future teacher or to complement the training of those who already work in the profession, enabling an articulation between undergraduate and graduate studies, as well as between theory and practice. The oriented teaching activity occurred in the first semester of 2020, in the discipline of History of Fashion and Clothing I, the Course of Fashion Design, and in the discipline of Logic and Argumentation I, of the Course of Philosophy, at the Franciscan University. Such choice was because the oriented teachers have initial training in these courses. In view of this new context, the objective is to discuss the challenges of Oriented Teaching related to teaching practice in higher education in the midst of the pandemic, also, to present the reports of the teaching experiences of two academics of this master's degree. The methodology adopted for the research is bibliographic with reports of experience of teaching activity. The teaching internship is an enriching and relevant experience in the teacher's professional training, enabling the construction and consolidation of concepts and overcoming career difficulties in teaching in higher education.

\section{Keywords: Covid-19, Teaching and learning. Remote mode, Post Graduate.}

\footnotetext{
${ }^{1}$ Licenciada em Filosofia. Mestranda em Ensino de Humanidades e Linguagens, Universidade Franciscana (UFN). Bolsista da Coordenação de Aperfeiçoamento de Pessoal de Nível Superior (CAPES). E-mail: clarice.r.machado@gmail.com ${ }^{2}$ Designer de moda pela Universidade Franciscana (UFN). Mestra em Ensino de Humanidades e Linguagens (UFN). E-mail: carolmcolpo@gmail.com

${ }^{3}$ Orientador - Licenciada em Pedagogia. Mestre e doutora em Educação pela Universidade Federal de Santa Maria. Coordenadora do Curso de Pedagogia da Universidade Franciscana (UFN) e professora adjunta do mestrado em Ensino de Humanidades e Linguagens (UFN). E-mail: elianeagalvao1@gmail.com
} 


\section{INTRODUÇÃO}

A complexidade do mundo atual nos faz pensar em transformações imprescindíveis na formação dos sujeitos de nossa sociedade e, se tratando de ambiente formal de ensino é imprescindível pensar em práticas pedagógicas que contribuam significativamente para o desenvolvimento do processo de aprendizagem dos estudantes. Compreendemos que a história da educação não é apenas um produto do pensamento e da ação daqueles que se encontram no âmbito educacional, mas está atrelada à vários fatores, tais como, a situação histórica de cada povo, ao caráter cultural, a estrutura social, a orientação política, a vida econômica, os ideais de educação, as modificações institucionais e os próprios métodos de ensino (LUZURIAGA, 1990). Por essa razão, quando se busca refletir sobre a educação é preciso considerar todos esses fatores históricos, sociais, culturais e políticos que influenciam a forma como se constitui a educação.

No decorrer da História, a educação foi sendo construída a partir de lutas sociais marcadas por vários acontecimentos. Assim sendo, é importante trazer para o debate questões que oferecem uma nova oportunidade de análise e de interpretação sobre a educação no contexto do mundo contemporâneo. Dentre os acontecimentos que marcam a história dos seres humanos, e consequentemente, da educação e contribui para refletir sobre ela, atualmente, tem-se a pandemia do coronavírus.

Não é novidade falar que hoje vive-se uma luta coletiva e mundial devido a pandemia causada pelo Covid-19. Embora as informações sobre a situação, desafios e mudanças de quando a pandemia chegou na China estivesse disponível nos meios digitais, ainda não estávamos passando por isso, dessa forma, parecia algo distante da realidade, principalmente, considerando que estávamos em outro continente. Agora, a circunstância é totalmente diferente, daquela de quem apenas observava a China, pois aquilo que parecia longínquo, chegou no Brasil, e daí em diante, tudo mudou. A vida das pessoas foi e está sendo alterada de forma exponencial e contínua. A quebra da normalidade que resulta de uma das mais acentuadas expressões já vividas, envolve uma crise de civilização capitalista, industrial, moderna e humana. Mas uma crise que não tem mais, somente o caráter econômico e de saúde, ela se caracteriza como a maior já vivenciada e traz desafios perpassando por todas as áreas, destaca-se aqui a educação, em especial o ensino e aprendizagem em tempos de pandemia. Além disso, a pandemia nos tirou de uma vida movida pelo piloto automático e faz-nos repensar nossas práticas, enquanto seres humanos e sociais.

Assim sendo, nesse artigo a discussão centra-se nos modos de pensar e realizar o ensino na educação superior a partir de uma experiência da disciplina de Docência Orientada, do Mestrado Acadêmico em Ensino de Humanidades e Linguagens da Universidade Franciscana (UFN). O objetivo é discutir os desafios da Docência Orientada relativa à prática docente no ensino superior em meio a pandemia, também, apresentar os relatos das experiências de docência de duas acadêmicas do referido mestrado, a partir do ensino remoto. 
A Docência Orientada visa a contribuir com a aprendizagem do futuro docente ou a complementar a formação daqueles que já atuam na profissão, possibilitando uma articulação entre a graduação e a pós-graduação, bem como entre a teoria e a prática e, consequentemente, aperfeiçoa o processo de qualificação dos mestrandos. A disciplina constitui-se por estudos teóricos acerca da docência no ensino superior, mediado pela professora ministrante da disciplina; o planejamento das aulas em conjunto com o professor(a) regente da disciplina na graduação e finalmente, a prática docente em sala de aula na graduação.

Nesse sentido, Bolzan e Santos defendem que "a possibilidade de interação entre a teoria e a prática proporciona ao mestrando aprender a ser professor e a atuar no ensino superior, pois muitos não têm experiência prática com a docência” (2007, p. 1). Por isso, torna-se fundamental buscar novas maneiras de organizar e de compreender os processos formativos dos docentes, tendo em vista que esses profissionais, ao desenvolverem seu trabalho constroem a sociedade, através da educação. Então, a docência oferece ferramentas que permite aos mestrandos a partir da experiência, refletir sobre a sua prática, a sua ação docente e construir mecanismos que contribuam para o aprender a ser professor, ressignificando suas práticas.

A atividade de docência orientada foi desenvolvida na disciplina de História da Moda e do Vestuário I, do Curso de Design de Moda, e na disciplina de Lógica e Argumentação I, do Curso de Filosofia, na Universidade Franciscana. Essa escolha deu-se porque as docentes orientadas possuem a formação inicial nos referidos cursos.

No primeiro dia de aula, na disciplina de Docência Orientada ofertada no curso do mestrado, tínhamos uma expectativa com relação às aulas no ensino superior e muitas ideias. A animação de trabalhar com o conteúdo que gostamos, ao mesmo tempo, o receio em voltar para o curso da nossa formação inicial na posição de professoras, marcaria o início da nossa docência. Contudo, passaram-se alguns dias e todo esse sentimento mudou quando o Covid-19 se instaurou no Brasil. Precisávamos lidar com a docência em meio a pandemia, com a nossa expectativa, com o desafio de assumir a turma, e somando a isso, mais do que nunca, o cuidado com nossas emoções e dos nossos alunos, porque todos estamos submersos em tantos sentimentos misturados, de perdas, tristeza, aflição, ansiedade, saudade, temor e solidão por causa do coronavírus. Nesse contexto, temos a atribuição de ajudar o aluno na sua formação, o que não se esgota apenas no racional, mas engloba a dimensão sensível e emocional dele. Diante disso, cabe questionar o que é essa pandemia?

A pandemia de Covid-19, é uma pandemia que está em curso com uma propagação mundial de um novo vírus com alta taxa de mortalidade que se caracteriza por uma doença respiratória aguda causada pelo coronavírus da síndrome respiratória aguda grave 2 (SARS-CoV-2). De acordo com a Organização Mundial de Saúde (OMS), as pessoas com Covid-19 apresentam um quadro clínico que varia de infecções assintomáticas a quadros respiratórios graves (BRASIL, 2020b). Apesar da China ser apontada como o local de origem do vírus, ainda não está claro qual foi a fonte original de transmissão para os seres humanos e nem de quando se tornou patogênica. 
Ainda não se tem vacina ou protocolo de tratamento consolidado para o Covid-19, mesmo ele tendo alto grau de transmissibilidade e cujas principais estratégias de combate, de acordo com a Organização Mundial da Saúde, são lavar as mãos com água limpa e sabão e se manter em casa (BRASIL, 2020a). Com as informações que estão disponíveis nas mídias, é possível perceber que os estudos com relação ao coronavírus e os seus desdobramentos é recente para todas as áreas, ainda há um caminho nebuloso pela frente e que será trilhado, em conjunto, por toda a humanidade. Diante desta breve exposição sobre o que é a pandemia de Covid-19, cabe deslocar a pesquisa, de imediato, para as reflexões das consequências que o coronavírus traz para a educação, em especial, para a prática docente no ensino superior.

Com os novos desafios que emergem com o Covid-19, torna-se necessário pensar em uma formação do professor que una as diferentes concepções sobre o professor, isto é, como uma pessoa real, como sujeito capaz de destrezas e como um profissional que toma decisões (GARCIA, 2005). O cenário atual, exige essa união que por muito tempo foi separada, pois essas concepções são consideradas de acordo com as diferentes abordagens, paradigmas ou orientações. As discussões sobre os processos formativos do professor, esteve por muito tempo atrelada a concepção de organização, como um conjunto de técnicas, porém, com as novas demandas do mundo e a complexidade na qual a sociedade está envolta, exige que esse processo seja concebido de outra maneira (BOLZAN; SANTOS, 2007).

De acordo com o Portal Desafios da Educação (2020), os efeitos da pandemia do novo coronavírus não ficam restritos às pessoas infectadas. Na educação, 1,5 bilhão de estudantes chegaram a ficar com aulas suspensas ou reconfiguradas ao redor do mundo. O contingente representa mais de 90\% de todos os estudantes do planeta, segundo atualização realizada pela Unesco, órgão da ONU para educação e cultura. Para o ensino superior, o MEC autorizou o ensino em meios digitais sob forma de substituição das aulas presenciais enquanto durar a pandemia através da Portaria n 544/2020 (BRASIL, 2020c). Assim, a recomendação do setor foi para não cancelar as atividades, mas fazer com que professores e alunos trabalhem juntos e de forma remota pela internet, por meio de ambientes virtuais de aprendizagem (AVA ou LMS, na sigla em inglês, ZOOM, Microsoft Teams etc).

Nesse contexto, a pandemia causada pelo coronavírus reacende uma velha discussão acerca da formação docente e da necessidade de contemplar pontos essenciais na construção de aprendizagem de professores, principalmente nos aspectos de tendências tecnológicas e de metodologias ativas. Nesse sentido, podemos considerar que a tecnologia exerce uma grande influência na vida das pessoas e no âmbito educacional. Hoje, mais do que nunca, ela se tornou essencial no novo modelo de ensino: o ensino remoto.

Colaborando com o pensar a formação docente não se pode deixar de fora da reflexão, os seguintes questionamentos: como se configura o ensinar e o aprender no ensino superior? Quais os modelos de ensino predominantes, eles ainda são adequados? Qual o modelo que precisa ser instituído para que a aprendizagem efetivamente aconteça, no cenário atual? Como o professor percebe-se 
dentro deste contexto e qual o seu papel? Em que medida as novas tecnologias contribuem para a formação do sujeito? Esses e outros questionamentos são importantes para o estudo, porque permitem reunir informações e explorar com mais profundidade o problema da pesquisa delineado da seguinte forma: Como dinamizar a docência nestes tempos que exige novas configurações de ensino, bem como do ser e fazer professor?

A metodologia adotada para a pesquisa é bibliográfica com relatos de experiência da atividade de docência, em meio a pandemia, das duas mestrandas do referido mestrado. Para a fundamentação teórica, tem-se como base os textos de (GARCIA, 2005); (BOLZAN; SANTOS, 2007); (FREITAS, 2008); (ANASTASIOU, 2015). Ademais, utiliza-se outras obras consideradas necessárias para auxiliar no desenvolvimento desta.

\section{SER PROFESSOR NA EDUCAÇÃO SUPERIOR NA CONTEMPORANEIDADE}

Esses desafios enfrentados pelo profissional docente torna-se uma questão central da contemporaneidade, pois emergem do contexto da sociedade do conhecimento, isto é, uma era em que os sujeitos vivem em constante aprendizagem. Nesse sentido, o conhecimento passou a ser o principal capital do seu trabalho, qualificando-o para atuar em diferentes contextos (KUMAR, 1998; LÉVY, 1998; DERTOUZOS, 2000). O desenvolvimento do docente caracteriza-se como um projeto elaborado ao longo da carreira que envolve tanto os aspectos da formação pessoal quanto profissional e organizacional.

\footnotetext{
Desse modo, abarca dimensões: pessoal, como o professor se desenvolve, quais são suas estratégias, suas formações; da profissão, como ele ao se desenvolver, auxilia na constituição da profissão professor; da instituição, como, em decorrência dos dois processos anteriores, o professor renova a instituição da qual ele faz parte, seja a escola ou universidade, com as funções a que lhes são inerentes e outras atribuídas; e por fim, da inovação escolar, ou seja, do ensino, que diz respeito à responsabilidade do professor buscar inovações para atender às demandas da sociais (SILUK; PAVÃO, 2014, p. 19).
}

Nessa perspectiva, percebemos que a prática docente resulta de outras dimensões que não se resume, unicamente, ao ensino aprendizagem, a educação, mas que ela é reflexo que esse docente tem de si, enquanto ser humano, de sua profissão, dos métodos e estratégias que seleciona para as aulas, como ele percebe o seu lugar dentro da instituição. E isso, é determinante para propor uma educação ativa, reflexiva, dinâmica, flexível, de forma a articular o processo de ensino aprendizagem aos métodos e objetivos pretendidos às ações educativas.

Com os avanços das tecnologias e da informatização da sociedade, o conhecimento e a informação adquirem um posicionamento privilegiado como fonte de poder e valor, e consequentemente, provocam mudanças na organização do trabalho e nas modalidades de aprendizagem. Nesse contexto, vale destacar que um dos elementos básicos de discussão da ação docente no ensino superior para 
atender às novas exigências, refere-se ao ensinar, ao aprender e ao apreender. Essas ações são muitas vezes consideradas e executadas como ações disjuntas, ouvindo-se inclusive de professores, afirmações do tipo: “eu ensinei, o aluno é que não aprendeu” (ANASTASIOU; ALVES, 2015). No entanto, a ação de ensinar não pode se limitar a simples exposição dos conteúdos, incluindo necessariamente um resultado bem sucedido daquilo que se pretende fazer, no caso, a apropriação do objeto de estudo. Por essa razão, é que as autoras Anastasiou e Alves (2015) defendem o processo de "ensinagem" no livro Processos de ensinagem na universidade.

O termo ensinagem é usado para indicar uma prática social complexa efetivada entre os sujeitos, professor e aluno, que engloba "tanto ação de ensinar quanto a de apreender, em processo contratual, de parceria deliberada e consciente para o enfrentamento na construção do conhecimento escolar, resultante de ações efetivadas na, e fora da, sala de aula" (ANASTASIOU E ALVES, 2015, p. 20). Assim sendo, as autoras esclarecem a importância em compreendermos a diferença entre aprender e apreender no processo de ensinagem.

O aprender, no entendimento das autoras, é o processo que se limita a ação de receber a informação e memorizar. Já o apreender não se trata de um verbo passivo, é mais amplo. "Significa segurar, prender, pegar, assimilar mentalmente, entender, compreender, agarrar”. Para apreender é preciso agir, exercitar-se, informar-se, tomar para si, apropriar-se, entre outros fatores (ANASTASIOU; ALVES, 2015, p. 19). É preciso distinguir quais dessas ações estão presentes na meta que estabelecemos ao ensinar. Se for apenas receber a informação de, bastará passá-la através da exposição oral. Nessa perspectiva, as autoras defendem que uma boa palestra é o suficiente para a transmissão da informação.

No entanto, se nossa meta se refere a apropriação do conhecimento pelo aluno, para além do simples repasse da informação, é preciso se reorganizar. Torna-se fundamental superar o aprender, que tem se resumido em processo de memorização, na direção do apreender, segurar, apropriar, agarrar, prender, pegar, assimilar mentalmente, entender e compreender. Diante disso, Anastasiou e Alves (2015) sugerem uma relação contratual, que se efetiva nos Programas de Aprendizagem, quando professor e aluno têm responsabilidades na conquista do conhecimento, adotando processos de parceria e colaboração. Um processo que seja compartilhado de trabalhar os conhecimentos, no qual conteúdo, forma de ensinar e assimilar, assim como obter resultados, estão mutuamente dependentes.

Para isso, evidencia-se a importância da mediação docente, que prepara e dirige as atividades e as ações necessárias e busca, nas estratégias selecionadas, levar os alunos ao desenvolvimento de processos de mobilização, construção e elaboração da síntese do conhecimento (VASCONCELOS, 1996). Sendo assim, o professor atua como mediador no processo de ensinagem e o aluno como autônomo do seu conhecimento.

Em conformidade com isso, Gabriel (2018, p. 93) afirma que "[...] a proliferação de conteúdo em virtude das novas possibilidades tecnológicas de produção, reutilização e distribuição que a internet propicia tende a gerar um ambiente mais rico em aprendizagem e criatividade do que em 
qualquer outra era". Desta forma, a educação também é afetada por esse processo e precisa adaptar-se às exigências advindas dessa nova sociedade. Para dar conta dessas novas demandas sociais, a universidade necessita de novas metodologias de aprendizagem e parâmetros de formação do profissional docente conjuntamente com as tecnologias de informação e comunicação, isto é, que a universidade considere essas mudanças causadas pelos impactos dessas novas formas de distribuição, apropriação e circulação do conhecimento.

Como a Tecnologia da Informação e Comunicação (TIC) pode abranger e ser usada em vários contextos, a sua definição pode ser bastante complexa e ampla. Porém Pinto (2005) define as Tecnologias de Informação e Comunicação como um meio para produzir, transmitir, armazenar, ascender e usar diversas informações, isto é, todos os meios são usados para tratar a informação e auxiliar na comunicação. Ainda nesse contexto, a evolução das TICs agregou facilidades ao cotidiano, permitindo realizar tarefas com muito mais praticidade (BLANCK, 2015). Ainda de acordo com a autora Júlia Caroline Blank (2015), faz-se necessário pensar em uma remodelagem de metodologias de ensino que comprovem que novas tecnologias podem ser grandes aliadas de forma a promover a integração com a educação. Pois a ascensão desse novo meio de comunicação agiu no modo de vida da humanidade, contribuindo especificamente para o fortalecimento do conceito de globalização, onde o mundo está mais semelhante, integrado, em termos socioculturais e políticos.

Desse modo, a utilização das TICs se tornou indispensável para uma proposta didática inovadora na área do ensino. Assim, uma educação de qualidade está inserida no contexto da informação e da formação de sujeitos que vive em sociedade. Alves e Tatsch (2015) argumentam que o docente precisa integrar-se às novas exigências que vão além do ensino aprendizagem dentro da universidade, seja em termos cognitivos, interesses ou expectativas dos discentes, enquanto seres que convivem em sociedade. No entanto, é importante deixar claro, que nesse momento, a formação docente terá um papel central: desmistificar o papel da tecnologia e reconhecer a importância do professor reafirmando a importância do uso de TICs como meio de aprendizagem e não como fim. Como docentes, identificamos essas transformações na sociedade, porém, não podemos ficar imune a elas, assumindo a posição de meros receptores.

É preciso compreender que as TICs proporcionam as ferramentas para ministrar aulas e os professores são os mediadores desse processo de ensino aprendizagem, pois a docência tem de ser uma mão de via dupla, isto é, os alunos e professores ensinam e aprendem mutuamente. O docente assume um papel muito importante se comparado àquele que vem assumindo nas últimas décadas, especialmente em contextos tradicionais de ensino. Como na sociedade da informação o conhecimento encontra-se diluído em organismos humanos e não humanos (meios digitais, tecnológicos), o ensinar e o aprender tomaram nova configuração.

Podemos aprender com outras pessoas sem precisar estar frente a frente, graças às mídias digitais, por exemplo, aulas por meio do ensino remoto através de videoaulas, ambientes virtuais de 
aprendizagem. O próprio aluno pode investigar na internet, ou seja, ampliou-se os detentores de informações. Isso alterou as práticas de ensino, por exemplo, houve a necessidade de mudança do perfil do professor, este passou a realizar uma espécie de curadoria da informação - pensar que a informação existe, mas como ajudar a selecionar o que o aluno se interessa e auxiliar em como ele torna esta informação um conhecimento. E do aluno que possui maior autonomia com relação ao seu processo de aprendizagem, pois pode recorrer a fontes variadas de insumo para adquirir informações, e por meio das conexões que estabelece ao longo desse processo, vai reforçar o que já sabe e avançar ao desconhecido (PRIMO, 2013; GABRIEL, 2018).

Diante disso, as pesquisadoras Bolzan e Santos (2007) destacam a aprendizagem compartilhada, tanto em relação ao processo construtivo de ser professor do ensino superior, quanto em relação ao processo inicial de preparação dos alunos como futuros profissionais. Com o enfoque na aprendizagem compartilhada, de parceria deliberada entre professor e aluno, Com a situação da pandemia, mais do que nunca, há a necessidade de se formar parceria entre os docentes e discentes, pois é uma situação nova para todos, e ambos estão aprendendo como agir, a se refazer neste cenário.

Assim, a educação está envolvida com o conhecimento social, pedagógico e pessoal para promover uma formação integral do discente. Isso significa que precisa considerar o contexto do mundo atual que se torna cada vez mais complexo, dinâmico que sofre mudanças e transformações pela influência da globalização, dos avanços tecnológicos e da diversidade cultural. Compreender que o conhecimento pedagógico precisa deixar espaço para que o aluno possa fazer as relações com outros saberes e fazeres, ou seja, não se limitar a transmissão de conteúdo, conhecimentos de modo desconexo da realidade. Além disso, é imprescindível ter o conhecimento do sujeito, sua personalidade, interesses e valores para saber o que pode ser feito para o desenvolvimento pessoal e participação social.

Nessa perspectiva, a educação exige um esforço transdisciplinar que seja capaz de rejuntar ciências e humanidades (MORIN, 2000), ou seja a forma como o ser humano se volta para si mesmo e procura refletir sobre seu papel no mundo e a própria compreensão da interação do universo. Pode-se dizer que estamos vivendo um momento ideal para essa reflexão, em meio a pandemia causada pelo Covid-19. Morin em entrevista ao Le Monde (2020), destaca

Essa epidemia nos traz um festival de incertezas. Não temos certeza sobre a origem do vírus: mercado insalubre de Wuhan ou laboratório vizinho, ainda não sabemos acerca das mutações que sofre ou poderá sofrer o vírus durante sua propagação. Não sabemos quando a epidemia regredirá e se o vírus permanecerá endêmico. Não sabemos até quando e em que medida o confinamento nos fará sofrer impedimentos, restrições e racionamento. Não sabemos quais serão as consequências políticas, econômicas, nacionais e globais das restrições trazidas por confinamentos. Não sabemos se devemos esperar o pior, o melhor, uma mistura dos dois: estamos caminhando para novas incertezas (LE MONDE, p. 1).

Dessa forma, o conhecimento se multiplica exponencialmente e, de repente, vai além da nossa capacidade de nos apropriarmos dele. É necessário se desapegar do conforto intelectual que carrega o 
horror à caminhos que os incomodam e os confrontam. Neste momento, lança-se um desafio da complexidade: como confrontar, selecionar, organizar adequadamente esse conhecimento, conectando-o e integrando incertezas.

Para Morin (2020), isso revela mais uma vez as deficiências do modo de conhecimento que nos foi inculcado, que nos faz separar o que é inseparável e reduzir a um único elemento aquilo que forma um todo ao mesmo tempo uno e diverso. De fato, a revelação avassaladora das mudanças pelas quais estamos passando é que tudo o que parecia separado está ligado, pois uma catástrofe na saúde, como esta pandemia, traz catástrofes em cadeia para tudo o que é humano. Ainda segundo o autor, a humanidade vive um complexo processo de transformações - atuando em escala global e local, e essas transformações redefinem e compreendem desafios dos papéis dos professores em meio ao caos. Logo, vale destacar que a docência é uma atividade complexa, pois não existem modelos ideais quando o assunto é docência. Acreditamos que cada turma, cada aluno, cada escola, universidade e/ ou instituição de ensino é singular. Por isso faz-se pertinente ter a sensibilidade de saber distinguir as diferenças de cada indivíduo e âmbito acadêmico que envolve peculiaridades e demanda conhecimentos de diferentes naturezas.

A complexidade que envolve a sociedade em sua totalidade exige que a formação docente seja compreendida como um processo dinâmico, reflexivo e inacabado, que se desenvolve aos poucos, um processo contínuo de ressignificação dos saberes e da prática. E o docente se torna produtor “de sua própria formação, no qual as suas representações, competências e conhecimentos, são o ponto de partida para seu desenvolvimento profissional (BOLZAN; SANTOS, 2007, p, 2). Isso equivale a dizer, que a relação entre aprender e ensinar transcende o domínio de conteúdo da área, ou seja, não adianta o professor saber o conteúdo específico a ser ensinado, mas ele, precisa implementar novas estratégias que mobilizem os estudantes a se apropriarem dos conhecimento e desenvolver as competências. Assim, o professor assume o papel de protagonista do processo educativo e uma abordagem reflexiva sobre a sua prática para repensar sua teoria de ensino, os esquemas, atitudes, os fazeres e os saberes pedagógicos que as transformações podem acontecer, havendo, assim, compromisso entre os participantes desse processo.

A partir dessas ponderações apresentadas e que fizeram parte da atividade da docência, vamos apresentar o nosso relato nos respectivos cursos de formação inicial, os quais são: Curso de Design de Moda e Filosofia.

\section{RELATOS DE EXPERIÊNCIA DA DOCÊNCIA}

O desafio do ser professor reside na busca de diferentes vias de acesso ao saber sem deixar de lado a formação das subjetividades, o seu desenvolvimento humano, as relações com a sociedade no âmbito cultural, social, científico e tecnológico, pois todos são essenciais para dar conta das exigências 
do mundo contemporâneo. "Portanto, a educação terá de considerar, além da especificidade, a questão do trabalho (competitividade, competências e habilidades) e a questão da utopia (escolha, sonhos e esperança)" (ALVES; TATSCH, 2015, p. 17). Assim, para chegar a resultados satisfatórios e pertinentes para os dias atuais, é preciso refletir sobre o que se considera ser professor nestes tempos. Além disso, emerge a necessidade dos professores se posicionarem como sujeitos do ato de conhecer, valorizando os conhecimentos que os alunos possuem, não se caracterizando como o detentor do saber.

\begin{abstract}
A gestão da aula não é algo estático, nem se reduz à aplicação de procedimentos, já que requer a ação-reflexão contínua e vigilante sobre a complexidade das relações que se estabelecem entre as intenções docentes e as expectativas discentes, bem como ao que emerge nessa interação. Trata-se de compreender que a aula é, em si mesma, um processo dinâmico, em que professor, alunos e o próprio objeto de conhecimento implicam-se entre si, (trans) formando-se no percurso de ensinar e de aprender (LUNARDI, 2015, p. 33).
\end{abstract}

Deste modo, precisam adotar uma perspectiva de aprendizagem compartilhada com os colegas de profissão e os seus alunos, refletindo e considerando cada contexto para a reconstrução do trabalho pedagógico (BOLZAN; SANTOS, 2007). A atividade de docência possibilitou o envolvimento nas diversas situações de ensino aprendizagem e nos constantes desafios da prática pedagógica e permitiu às mestrandas ter o primeiro contato com a docência no ensino superior.

\title{
EXPERIÊNCIA NO CURSO DE DESIGN DE MODA
}

Considerando a educação um ato social, vale salientar que ela tem se ter transformadora (FREIRE, 1997), com o objetivo de não só transmitir conhecimentos, mas sobretudo formar cidadãos com princípios éticos e morais para o mundo. A partir disso, defende-se o ensino da história da moda como processo crítico e reflexivo, destacando a importância do desenvolvimento da consciência crítica dos acadêmicos de design de moda.

O estágio de docência orientada, ministrado na disciplina de História da Moda e do Vestuário I, foi planejado juntamente com a professora responsável pela disciplina. Devido à pandemia, ocorreram alterações no calendário acadêmico do semestre, as quais foram estipuladas pela coordenação do curso de design de moda. Sendo assim, o planejamento foi reorganizado e para o desenvolvimento da docência orientada foram ministradas oito aulas de modo remoto, durante os meses de maio e junho de 2020: seis encontros com atividades síncronas por meio de videoconferências pela plataforma Teams duas aulas com atividades assíncronas, com materiais postados no Ambiente Virtual de Aprendizagem (Moodle).

O objetivo central era ministrar aulas sobre os períodos históricos da moda dos séculos XVII e XVIII. Os séculos XVII e XVIII contemplaram os reinados do Rei Luís XIV, rei Luís XV e rei Luís XVI e sua esposa Maria Antonieta, figuras essenciais para estudarmos a História da Moda e suas 
contribuições por meio da cultura das aparências. Também foram abordados os períodos artísticos Barroco e Rococó e suas contribuições para o apelo visual da moda a partir dos séculos XVII, XVII até os dias de hoje.

Em seguida, para realização das aulas, foram enviados textos para leituras prévias a fim de propor uma reflexão sobre as informações específicas de cada período histórico da moda, sendo capaz de discerni-las e reinterpretá-las conforme o seu objeto de estudo. A partir da leitura e apresentação dos textos, foram propostas atividades que estimulam à criatividade dos acadêmicos com diferentes questionamentos em cada aula, pois enquanto futuros designers de moda, os acadêmicos de moda precisam compreender que a criatividade nasce da pesquisa, e quanto mais pesquisar, mais ideias vão surgir para futuros projetos de moda. Além disso, o professor, enquanto mediador, deve instigar os alunos a pesquisar sobre as temáticas abordadas na aula.

Diante disso, as atividades propostas tinham a intenção de despertar o olhar atento dos acadêmicos estimulando a reflexão crítica em relação à compreensão da moda enquanto fenômeno social e não apenas mercadológica, pois a moda envolve uma esfera muito maior do que fazer roupas. No entanto, compreender a importância da História da Moda para a sociedade é um desafio, pois a moda, durante muito tempo, foi vista como supérflua.

Nessa perspectiva é preciso destacar que estudar a moda e sua relação com a história "é debruçar-se não apenas sobre as diversas mudanças de gostos ou transformações de formatos de mangas, vestidos, cores, gravatas ou paletós - ainda que isso também faça parte da história da moda" (DEBOM, 2019, p. 14), mas sobretudo estudar a moda é olhar para o passado e tentar compreender a relevância da moda enquanto fenômeno social e sua contribuição para a sociedade. Moda, originada do latim "modus", literalmente "medida", o termo moda passou a expressar valores tão diversos como conformidade e relações sociais, rebelião e excentricidade, aspiração social e status, sedução e encanto" (FOGG, 2013, p. 8). De acordo com dicionário Brasileiro da Língua Portuguesa, a palavra moda tem o seguinte significado:

moda, s. f. (fr. mode). 1. Uso corrente. 2. Forma atual do vestuário. 3.Fantasia, gosto ou maneira como cada um faz as coisas. 4. Cantiga, ária, modinha. 5. Estat. $\mathrm{O}$ valor mais frequente numa série de observações. 6. Sociol. Ações contínuas de pouca duração que ocorrem na forma de certos elementos culturais (indumentária, habilitação, fala, recreação etc.). S. f. Pl. Artigos de vestuário para senhoras e crianças. Antôn.: anti-moda. ((FERREIRA, 1980, p. 1156).

Ainda nesse sentido, conforme defende Marnie Fogg (2013), a moda é uma espécie de mecanismo que direciona diversas esferas da nossa sociedade. Para isso, portanto, a dimensão epistemológica do planejamento da docência orientada foi construída a partir do conceito de pensamento complexo de Edgar Morin (2007) que defende, em sua Teoria da Complexidade, a ideia de que "pensar a complexidade é o maior desafio do pensamento contemporâneo", pois exige uma reforma do nosso "modo de pensar". 
Dessa forma, estudar a moda sob a perspectiva da Teoria da Complexidade é propor um novo modelo de paradigma de formação do conhecimento ao contrariar os princípios da ciência clássica e considerar, sobretudo, a interdisciplinaridade para a compreensão de problemáticas contemporâneas na sociedade. É necessário, então, inferir uma reforma do pensar sobre a compreensão da moda, pois a maioria dos indivíduos reduze seu significado às roupas, o que por um lado não está totalmente equivocado, uma vez que é pela vestimenta que se consegue materializar a moda com mais facilidade (SANTOS; HELD 2018).

No entanto, de acordo com Svendsen (2010) a moda deve ser interpretada além da indumentária: adentra todas as áreas referentes ao consumo e sua lógica invade a arte, a política e a ciência, caracterizando-se como um fenômeno que reside no centro da sociedade. Além disso, apesar da recorrente tentativa de definição da moda, não há ainda alguma que esgotasse por completo seu significado. Portanto, a moda trata-se de um fenômeno complexo

A moda é outro ótimo exemplo de complexidade. Para trabalhar com moda não basta fazer desenhos e dispô-los em uma coleção. É preciso ser capaz de dar vida ao universo complexo, interligando saberes de diversas áreas; estar atento aos movimentos sociais e culturais, compreender psicologia [...] É preciso ter uma vista bem clara da história da humanidade e da história da arte; estar atento às tecnologias têxteis e á administração de negócios [...] (TRONCA, 2009, p. 30).

Para tanto, é preciso repensar o escopo de atestar a complexidade da moda, bem como uma possível compreensão dela em sua totalidade. Ainda que por muito tempo alguns teóricos consideraram-na algo superficial e indigno de estudos aprofundados, o exercício da moda se apresenta consciente ou inconscientemente para todos, mostrando-se capaz de refletir a sociedade contemporânea (SANTOS; HELD, 2018).

Logo, a pretensão, aqui, está voltada à problematização e a reforma do pensamento (MORIN, 2014) acerca do processo de ensino-aprendizagem da história da moda que, muitas vezes, limita-se na descrição das vestimentas nos períodos históricos da humanidade. Vale destacar que muito se pode fazer com a quebra dos paradigmas de ensino que simplificam o conhecimento de História, por muito tempo entendido como um saber firmado apenas na narração de fatos, sem levar em conta a reflexão crítica e complexa dos fatos, pois contar a história sem reflexão não é suficiente para entender o passado e agir no presente pensando nas gerações futuras.

Assim sendo, espera-se que o estágio de docência orientada tenha propiciado reflexões metodológicas muito mais amplas que o domínio de técnicas de confecção, com foco em um processo educativo crítico e criativo. Por fim, a experiência da docência orientada foi desafiadora pelo fato de termos que nos reinventar diante do ensino de forma remota. Além da experiência da docência contribuir muito para a minha formação docente, foi essencial para a minha formação enquanto pesquisadora, pois exigiu muita pesquisa e criatividade para preparação das aulas para que não se tornassem cansativas e estimulasse a pesquisa e realização das atividades dos acadêmicos. 


\section{EXPERIÊNCIA NO CURSO DE FILOSOFIA}

“A Filosofia se constrói e se enriquece, sobretudo, nas perguntas e nos questionamentos [...]. A curiosidade, o desconhecido, movem as perguntas" (MARTINAZZO, 2016, p. 47), ela tem o propósito de nos fazer pensar acerca de quem somos e do que fazemos na vida cotidiana. E esse cenário de incertezas, dúvidas, caótico que estamos inseridos, se torna bastante propício para o filosofar. Frente a este pensamento, o estágio de docência orientada, ministrada na disciplina de Lógica e Argumentação I, foi planejado em conjunto com o professor responsável pela disciplina e resultou em oito encontros com os alunos em modalidade remota. O objetivo era desenvolver as competências argumentativas e lógicas dos estudantes mediante o estudo de técnicas de análise conceitual e do silogismo aristotélico. Os conteúdos ministrados foram proposições, sentenças, validade, forma, correção, verdade, raciocínio, argumento dedutivo, argumento indutivo e silogismo aristotélico.

O conteúdo de Lógica exige bastante exercícios e é considerado difícil por muitos estudantes e até mesmo professores formados em Filosofia, ou seja, já era difícil nas aulas presenciais, quem dirá em modalidade remota. Com essas observações e cuidados, o planejamento foi pensado de modo que não ficasse pesado, cansativo para os estudantes e não os obrigassem a ficar mais de duas horas sentados em frente ao computador. E, também que o conteúdo não fosse trabalhado de maneira sucinta e muito rápida que não desse conta de possibilitar a aprendizagem por parte dos discentes dos conceitos e da aplicação deles na realidade.

Frente a essas dificuldades com o conteúdo de Lógica, a situação atual que o coronavírus nos colocou é ainda mais delicada, modo de ensino, de educação na qual o professor torna-se um mediador. Esse modo de fazer aulas caracterizado como ensino remoto nos colocou diante do intenso uso das tecnologias de informação e comunicação, o que nos coloca diante do desafio de aprofundar conhecimentos técnicos e pedagógicos-Nesse contexto, para que a educação tenha qualidade é preciso identificar as prioridades da realidade social e pedagógica e adequar de acordo com a consecução dos objetivos, e no caso, compreender a situação que a pandemia do coronavírus nos coloca.

Assim, realizar as aulas de modo remoto, na prática da docência orientada foi um desafio, uma vez que é uma realidade ainda não conhecida. Contudo, além de ser remoto, era para futuros profissionais do curso de filosofia e então o cuidado e o nervosismo duplicaram, era um contexto totalmente novo e somando a isso, tinha a situação da quarentena, o isolamento social por causa do Covid-19. Nesse contexto de ensino e aprendizagem online o professor se torna um mediador, coadjuvante, não está mais no centro do processo. O professor, nessa nova função, tem um papel fundamental para a educação, pois garante a inter-relação personalizada e contínua do aluno no sistema e viabiliza a articulação necessária entre os elementos do processo e execução dos objetivos propostos (PRADO, 2012).

Não há essa necessidade de dominar e transmitir todo o conteúdo ou conhecimento da área, porque as informações estão disponíveis e a fácil acesso para os alunos, mas precisa auxiliar na forma 
como este recebe a informação e como utilizá-la e torná-la, de fato, conhecimento. Nesse viés Masetto defende que "o papel do professor como educador responsável pela mediação pedagógica, que estimule a aprendizagem do aluno como processo pessoal e grupal, oriente seus trabalhos, discuta com ele suas dúvidas, seus problemas, incentivando a avançar no processo do conhecimento” (2004, p. 200).

Ao atuar nesse viés o docente pode assumir uma postura mais ou menos colaborativa, dependendo do nível de autonomia do discente, pois nessa modalidade de ensino remoto, não é tão frequente recorrer à figura do professor. O docente trabalha por meio de tecnologias, contribuindo para sua aprendizagem com mensagens, recados e orientações por meio do ambiente virtual de aprendizagem (AVA), e-mail, Whatsapp, internet e outros, não chegando a atuar pessoalmente com esse aluno. Os “"...] AVAs configurados para proporcionar experiências em redes colaborativas retiram o professor da frente da sala de aula e o deslocam para os bastidores ou para junto dos alunos" (PAIVA, 2010, p. 368).

De modo geral, o método adotado e que perpassa todas as aulas é bastante conhecido na Filosofia, a experiência filosófica ou a experiência com pensamento conceitual, o qual se divide em quatro etapas. A primeira etapa é a sensibilização, momento inicial em que se ganha a atenção e o afeto do estudante com o tema a ser trabalhado empregando fatos, ideias, exemplos do universo cultural deles para auxiliar na assimilação. De acordo com Lima e Grillo "[a] situação elaborada relaciona-se a acontecimentos do cotidiano, da realidade do estudante e tem a intenção de mobilizar nele a reflexão e a criatividade" (2008, p. 26). A segunda etapa é a problematização do tema para despertar o interesse e a curiosidade do aluno através de questionamentos, configurando essa, a experiência filosófica propriamente dita.

Ao tomar como ponto de partida a problematização, utilizando exemplos da realidade do aluno, o docente tem a intenção de propiciar ao estudante oportunidade de explicitar suas idéias iniciais sobre o tema. Tal movimento deixa claro que, para o professor, o estudante não é tabula rasa; é, sim, um sujeito possuidor de conhecimentos oriundos de experiências, internalizados em distintos espaços sociais e culturais, incluindo-se aí os ambientes escolarizados que tenha frequentado (LIMA; GRILLO, 2008, p. 27).

A terceira etapa é a investigação, que se encontra entre o problema e o conceito, investigar o que se passa durante o processo que gerou o conceito. Nessa etapa se estuda os filósofos e textos filosóficos que auxiliaram na construção do conceito, da sistematização, as implicações para compreendê-lo racionalmente. E a etapa final é a conceituação, na qual se efetiva o ato filosófico, onde os estudantes recriam o conceito, por intermédio dos questionamentos, problematização, da interpretação e dos argumentos que se serve para o entendimento do conteúdo (GALLO; ASPIS, 2009). Além disso, todas as aulas eram gravadas para o posterior acesso dos alunos tanto dos que participaram da aula quanto os que não conseguiram por outros fatores.

A partir da escolha deste método e da forma como as aulas ocorrem, podemos dizer que se tem como base "uma pedagogia centrada na relação aluno, professor e objeto de conhecimento, quando a ênfase deixa de ser o professor e também o aluno para priorizar as relações de ambos com 
o objeto de conhecimento, implicando-se mutuamente como sujeitos do processo" (LIMA; GRILLO, 2008, p. 22). Com base no desenvolvimento das aulas e o acompanhamento individual nos AVAs, era pensado outras estratégias para as próximas aulas, por essa razão o planejamento estava sendo reconstruído de uma semana para a outra, pois emergia outras questões que precisavam ser levadas em consideração. A reconstrução do planejamento ocorria por causa da reflexão sobre a prática, que é fundamental para a construção do conhecimento e a própria formação do profissional docente. Nesse sentido Freire ressalta que "é pensando criticamente a prática de hoje ou de ontem que se pode melhorar a próxima prática" (1998, p. 44).

\section{CONSIDERAÇÕES FINAIS}

A docência orientada aprimora a formação dos mestrandos, contribui para a melhoria de qualidade do processo de ensino e aprendizagem, promovendo a articulação entre a teoria e a prática. Isso ocorre porque ela oferece ferramentas que permite aos mestrandos a partir da experiência, refletir sobre a sua prática, a sua ação docente e construir mecanismos que contribuam para o aprender a ser professor. A experiência de docência nessas disciplinas acrescentou muito para a formação das mestrandas, porque além da prática docente em sala de aula no ensino superior também realizamos estudos teóricos acerca da docência no ensino superior e o planejamento das aulas nas disciplinas da graduação, consistindo, dessa maneira, um processo teórico-prático reflexivo como docente, além de pesquisadora.

O contato com os alunos de graduação, a preparação e a execução das aulas fizeram com que adquiríssemos uma postura mais madura e responsável como professoras. As atividades de docência possibilitaram experiências significativas, pois a realidade prática é necessária para consolidar conhecimentos adquiridos.

Sob a perspectiva de que o conhecimento está distribuído em diferentes meios e que está disponível ao aluno, entendemos que o docente assume um papel de mediador ao longo do processo, sendo relevante para que a aprendizagem aconteça, porque ativa as conexões necessárias para a construção do conhecimento. O estágio docência constitui-se, portanto, como uma experiência enriquecedora e de grande relevância na formação profissional docente, possibilitando a construção e consolidação de conceitos e a superação de dificuldades da carreira da docência no ensino superior.

\section{REFERÊNCIAS}

ALVES, M. A.; TATSCH, K. J. S. A relação entre Universidade e Escola: complexidade, educação e conhecimento na formação de professores. In: Epistemologia, interdisciplinaridade e formação de professores. Nova Petrópolis: Nova Harmonia, p. 09-22, 2015. 
ANASTASIOU, L. G. C. Processos de ensinagem na universidade: pressupostos para as estratégias de trabalho aula. 10. ed. Joinville, Santa Catarina: Univille, 2015.

BLANK, J. C. Uso das redes sociais em sala de aula: vantagens e desvantagens. In: Seminário Internacional de Educação no Mercosul, p. 1-14, 2015. Universidade de Cruz Alta, Cruz Alta.

BOLZAN, D. P. V.; SANTOS, E. G. Docência Orientada: uma possibilidade de aprendizagem docente. In: IV Simpósio de Educação Superior: Desenvolvimento Profissional Docente e I Fórum de Pesquisadores em Educação Superior, 2007, Santa Maria. IV Simpósio de Educação Superior: Desenvolvimento Profissional Docente e I Fórum de Pesquisadores em Educação Superior. Santa Maria, 2007. Disponível em: https://bit.ly/38pubvj. Acesso em: 21 maio 2020.

BRASIL. Organização Pan-americana da Saúde. Folha informativa: covid-19 (doença causada pelo novo coronavírus). COVID-19 (doença causada pelo novo coronavírus). 2020a. Disponível em: https://bit.ly/36n86ea. Acesso em: 26 maio 2020.

BRASIL. Ministério da Saúde. Sobre a doença: Coronavírus (Covid-19). Disponível em: https://bit.ly/ 2GMHH0O. Acesso em: 27 maio 2020b.

BRASIL. Portaria n ${ }^{\circ}$ 544, de 16 de Junho de 2020. Dispõe sobre a substituição das aulas presenciais por aulas em meios digitais, enquanto durar a situação de pandemia do novo coronavírus - Covid-19, e revoga as Portarias MEC n 343, de 17 de março de 2020, n 345, de 19 de março de 2020, e $n^{\circ} 473$, de 12 de maio de 2020. Diário Oficial da União: seção 1, Brasília, DF, ed. 114, p. 62, 2020. Disponível em: https://bit.ly/2I16vx6. Acesso em: 05 ago. 2020c.

DEBOM, P. ; BORGES, C.; MONTELEONE, J. A história na moda, a moda na história. São Paulo: Alameda, 2019.

DERTOUZOS, M. L. O que será: como o novo mundo da informação transformará nossas vidas. São Paulo: Companhia das Letras, 2000.

FOOG, M. Tudo sobre moda. Rio de Janeiro: Sextante, 2013.

FREIRE, P. Pedagogia da autonomia: saberes necessários à prática educativa. 8. ed. São Paulo: Paz e Terra, 1998. 
GABRIEL, M. Você, eu e os robôs: pequeno manual do mundo digital. São Paulo: Atlas, 2018.

GALLO, S.; ASPIS, R. Ensinar Filosofia: Um livro para professores. São Paulo: Ed. Atta, 2009.

GARCIA, C. M. Formação de professores: para uma mudança educativa. Porto: Porto Editora, 2005.

LE MONDE. Entrevista de Edgar Morin por Nicolas Truong. Disponível em: https://bit.ly/32rKjc4. Acesso em: 06 de maio de 2020.

LÉVY, P. A Máquina Universo: criação, cognição e cultura informática. Porto Alegre: Artmed, 1998.

LIMA; V. M. R.; GRILLO, M. C. O fazer pedagógico e as concepções de conhecimento. In: FREITAS, A. L. S. A gestão da aula universitária na PUCRS. Porto Alegre: EDIPUCRS, p. 21-31, 2008.

KUMAR, K. Da sociedade pós-industrial à pós-moderna: novas teorias sobre o mundo contemporâneo. Rio de Janeiro: Jorge Zahar, 1998.

LUNARDI, E. M. Planejamento Interdisciplinar e Gestão da Aula. In: Epistemologia, interdisciplinaridade e formação de professores. Nova Petrópolis: Nova Harmonia, p. 33-45, 2015.

LUZURIAGA, L. História da educação e da pedagogia. 18. ed. São Paulo: Editora Nacional, 1990.

MASETTO, M. Inovação na educação superior. Interface - Comunicação, Saúde, Educação, São Paulo, v.8, n.14, p. 197-202, 2004. Disponível em: https://bit.ly/32tZm4R. Acesso em: 20 jun. 2020.

MARTINAZZO, C. J. A Filosofia e a Filosofia da Educação em Elo Recursivo. In: MARTINAZZO, C. J.; BARBOSA, M. G.; DRESCH, O. I. A educação escolar em um mundo complexo e multicultural. Ijuí: Unijuí, p. 45-66, 2016.

MORIN, E. A cabeça bem-feita: repensar a reforma, reformar o pensamento. 21. ed. Rio de Janeiro: Bertrand Brasil, 2014.

MORIN, E. Os sete saberes necessários à educação do futuro. Tradução de Catarina Eleonora F. da Silva e Jeanne Sawaya; revisão técnica de Edgard de Assis Carvalho. 2. ed. São Paulo: Cortez; Brasília, DF: UNESCO, 2000. 
PAIVA, V. L. M. O. Ambientes virtuais de aprendizagem: implicações epistemológicas. Educação em Revista, Belo Horizonte, v. 26, n. 3, p. 353-370, 2010. Disponível em: https://bit.ly/3pdn27d. Acesso em: 22 jun. 2020.

PINTO, Á. V. O conceito de tecnologia. v. 1. Rio de Janeiro: Contraponto, 2005.

PRADO, C. et al. Espaço virtual de um grupo de pesquisa: o olhar dos tutores. Revista da Escola de Enfermagem, São Paulo: USP, v. 46, 2012. Disponível em: https://bit.ly/38ptD8J. Acesso em: 22 jun. 2020.

PRIMO, A. Interações mediadas e remediadas: controvérsias entre as utopias da cibercultura e a grande indústria midiática. In: Alex Primo. (Org.). Interações em rede. Porto Alegre: Sulina, p. 13-32, 2013.

STEVENSON, Nj. Cronologia da moda: de Maria Antonieta a Alexander McQueen. Tradução Maria Luiza X. de A. Borges. Rio de Janeiro: Zahar, 2012.

SVENDSEN, L. Moda: uma filosofia. Rio de Janeiro: Zahar, 2010.

SILUK, A. C. P. ; PAVÃO, S. M. O. A formação de professores a distância: ser professor na contemporaneidade - deveres e fazeres na educação especial. In: Atendimento Educacional Especializado: Contribuições para a Prática Pedagógica. Santa Maria: UFSM, p. 17-31, 2014. 